\title{
Prevalence of smoking among bar workers prior to the Republic of Ireland smokefree workplace legislation
}

\begin{abstract}
Background Few studies have examined smoking behaviour among bar workers, an occupational group traditionally exposed to high levels of secondhand smoke. This study set out to: (1) establish baseline prevalence of smoking and cigarette consumption among Cork bar workers prior to the introduction of the Republic of Ireland's (ROI) smokefree workplace legislation (29th March 2004); (2) compare gender- and age-specific smoking rates in Cork bar workers with the equivalent occupational classes within the general population; (3) estimate the adjusted odds of being a smoker for Cork bar workers relative to the general population.
\end{abstract}

Methods A cross-sectional random sample of bar workers in Cork city and a cross-sectional random telephone survey of the general population (ROI) were conducted prior to the smokefree legislation.

Results 129 bar workers were enrolled and 1240 individuals from the general population. Self reported smoking prevalence among Cork bar workers was 54\% (58\% using cotinine-validated measures), with particularly high rates in women (70\%) and 18 to 28 year olds (72\%). The overall self reported rates in the general population sub-sample were substantially lower at 28\%; $28 \%$ in women and $36 \%$ among 18 to 28 year olds. Bar workers were twice as likely to be smokers as the general population sub-sample (adjusted odds ratio $=2.15,95 \%$ CI 1.45 to 3.17 ).

Conclusions Cork bar workers constitute an occupational group with an extremely high smoking prevalence. In addition to high secondhand smoke exposure prior to the smokefree legislation, this makes bar workers a high risk group for smoking-related illnesses.

Key words: Smoking prevalence, legislation, bar workers, smoking ban, tobacco control 


\section{Introduction}

For many years legislation in Ireland has prohibited smoking in most public places, providing protection for many workers. However much of the services industry, including pubs, was exempt. On the 29th March 2004 the Republic of Ireland (ROI) became the first European country to introduce nationwide smokefree workplace legislation for all workplaces including pubs and restaurants. Smoking is now prohibited in enclosed work places with few exceptions.

The Irish services industry, as in other countries, is low paid and largely non-unionised, a situation conducive to poor health behaviours. Bar workers can be considered a highly vulnerable group whose health would be expected to benefit greatly from a smokefree work environment for two reasons. Firstly, without smoking bans in place, bar workers are exposed to high levels of secondhand smoke at work. ${ }^{12}$ After the introduction of the smokefree workplace legislation in Ireland, cotinine levels dropped in non-smoking bar workers indicating significant reductions in secondhand smoke exposure. $^{34}$

Secondly, research suggests that bar workers constitute an occupational group with a high proportion of active smokers. Jones et al., ${ }^{5}$ found a $40 \%$ prevalence in hospitality workers in New Zealand, and Bang \& $\mathrm{Kim}^{6}$ reported a smoking rate of $44.5 \%$ among waiters and waitresses and $39 \%$ in those working in eating and drinking venues including pubs. Although the smokefree workplace legislation in Ireland was introduced as a measure to protect workers from secondhand smoke, the policy might also result in decreased smoking in the working population. Corroborating evidence for beneficial effects of workplace smoking restrictions on smoking prevalence and consumption rates has been reported by several authors. ${ }^{7-11}$ However non-representative samples and lack of comparison with the occupation-specific general population smoking rates of the respective countries limit the interpretation and generalizability of these findings.

Little is known about smoking rates in hospitality workers in Ireland although anecdotal evidence suggested that the rate of smoking among Irish bar workers was high. In order to establish smoking prevalence estimates for this group we enrolled a random sample of Cork city bar workers comprising floor staff, bar managers and owners. The objectives were (1) to establish a baseline prevalence of smoking and cigarette consumption among Cork bar workers prior to the introduction of the smokefree workplace legislation; (2) to compare gender- and age-specific smoking rates in Cork bar 
workers and in the equivalent occupational classes within the general population; and (3) to estimate the adjusted odds of being a smoker for Cork bar workers relative to the general population (subsample).

This study provides the first estimates of smoking prevalence and cigarette consumption in bar workers adjusted to enable comparisons with the general population.

\section{Methods}

We used two datasets for this study: 1) bar workers from Cork City, part of a larger study, the 'AllIreland bar study' reported elsewhere ${ }^{3}$; 2) a subset from a general population (ROI) telephone survey conducted by TNS mrbi, a commercial research company.

\section{Sample selection}

\section{Bar workers}

A three step cluster sampling strategy was used. First, 300 streets were randomly selected from a list of all Cork city streets (obtained from Cork City Corporation), using the random number generator in SPSS 12.0.1 (SPSS, Chicago, IL). Second, all pubs located on these 300 streets were selected resulting in 171 pubs representing $44 \%$ of the approximately 385 pubs in Cork city. Third, bar workers from these 171 pubs were enrolled in the study by randomly selecting up to two bar workers present at the time of the visit. If only one/two worker(s) was/were present at the time of the visit, only one/two worker(s) was/were selected. If a randomly selected bar worker was unable or unwilling to participate, a replacement bar worker was then randomly selected (if possible) from the same pub. Permission to interview was sought from either the manager/owner or senior staff present.

Participants were interviewed in the pub where they worked by trained interviewers between January and March 2004 (before implementation of the smokefree workplace legislation). If the selected bar worker was busy a more suitable time for interview was arranged. Only those actively involved in everyday tasks within the pub and who were over 18 years were eligible. We enrolled both smoking and non-smoking bar workers and all occupational positions i.e. owners, managers, full-time and parttime bar staff. Follow-up post-ban surveys were completed one and two years later, but will not be detailed here. 


\section{General population sub-sample}

General population data were obtained from an ongoing national monthly telephone survey of 1,000 randomly selected individuals ( $>15$ years) during the same time period as the bar workers survey (January to March 2004). Participants were selected based on randomly generated phone numbers; targets were met in relation to gender, age, occupational class and region. For comparison purposes the general population sample was restricted to participants of similar age (18 years and over) and with occupations equivalent to bar workers. This sample is referred to as the general population subsample. We used un-weighted data as we compared estimates within age, gender and occupational class strata.

\section{Measures}

\section{Bar workers}

Survey administration and salivary cotinine sampling procedures are described in more detail elsewhere. ${ }^{3}$

\section{Sociodemographics}

Participants were asked about their gender, age, and occupational position as an indicator of occupational class. Occupational class was determined by involvement in the pub: owners and managers were categorised as 'manager' (occupational class C2), temporary and permanent staff as 'staff' (occupational class DE). The term 'bar worker' refers to the entire sample. The occupational class classification was taken from the ROI Central Statistics Office (CSO) ${ }^{12}$ classification which is based on the UK Standard Occupational Classification. ${ }^{13}$

\section{Smoking status}

Participants were asked about their current smoking status, average cigarette consumption per day and smoking history. Two different measures of smoking status were used for bar workers: 'self reported' smoking status and 'self reported and cotinine combined' smoking status. Self reported smoking status (self reported current smoker versus current non-smoker) was used when comparing bar workers with the general population sub-sample.

Self reported and cotinine combined smoking status was obtained by validating self reports by cotinine where possible. Non-smokers were defined as those who self reported as current nonsmokers and had cotinine concentration levels <20ng/ml (113.6nmol/l). ${ }^{3}$ Smokers were defined as those who self reported as current smokers plus those who self reported to be non-smokers but with 
cotinine concentration levels of $\geq 20 \mathrm{ng} / \mathrm{ml}(113.6 \mathrm{nmol} / \mathrm{l})$. In cases where cotinine was not available due to insufficient samples or refusals, the self reported smoking status was used (28 cases). The self reported and cotinine combined measure was used to provide a more accurate estimate of the smoking prevalence in bar workers as it takes potential under-reporting of smoking into account.

\section{General population sub-sample}

Sociodemographics and smoking status

Participants were asked about their gender, age group, self reported smoking status ('do you smoke $>1$ cigarette per week'), self reported cigarette smoking consumption and occupation. Occupation classes equivalent to the bar managers and owners (occupational class $\mathrm{C} 2$ ) and bar staff (occupational class DE) were selected.

\section{Statistical analysis}

Data analysis was conducted using SPSS 12.0.1 (SPSS, Chicago, IL). Pearson's chi square or Fisher's exact test was used to examine gender, age and occupational class patterns in prevalence. The MannWhitney $\mathrm{U}$ test and the Kruskall Wallis $\mathrm{H}$ test were used to test for differences in consumption by sociodemographic characteristics. Logistic regression models were built for both samples with smoking status as outcome, adjusting for gender, age and occupational class.

\section{Results}

\section{Study participation}

Study participation is shown in Figure 1. Of the 171 pubs identified, 98 pubs participated, 30 were not eligible because they were no longer in business, eight pubs refused and 35 could not be surveyed due to time constraints (pub participation rate: 98/141=69.5\%). Altogether 129 bar workers were enrolled in the study; 67 pubs had one and 31 pubs had two participants interviewed. A replacement bar worker was required in $9 \%$ of cases.

Of the 2460 individuals enrolled in the national telephone survey over the three months, there were 1240 participants 18 years and over with occupational class equivalent to the bar workers.

Table 1 shows the demographic characteristics of the participating bar workers and the general population sub-sample. Sixty-nine percent of participating bar workers were male, with mean age 33 years; 56 percent were temporary or permanent staff (equivalent to occupational class DE) and the 
remaining $44 \%$ were either owners or managers (equivalent to occupational class $\mathrm{C} 2$ ). In comparison to the general population sub-sample, bar workers were more likely to be male and younger ( $88 \%$ under 49 years of age compared to $52 \%$ ).

\section{Bar worker smoking prevalence: self reported and cotinine combined}

Table II shows the prevalence of smoking among Cork bar workers by gender, age and occupational class. The overall prevalence of smoking (self reported and cotinine combined) in bar workers was $58.1 \%$ (95\% CI 49.5-66.6); 70\% of female bar workers were smokers compared to $53 \%$ of male bar workers being smokers $(\mathrm{p}=0.067)$. Smoking prevalence was $72.3 \%$ in the 18 to 28 year olds but decreased significantly with age. Staff had a significantly higher smoking prevalence $(68 \%)$ than managers $(46 \%)(\mathrm{p}=0.01)$.

\section{Bar worker prevalence (self reported) in comparison to the general population sub-sample}

We compared the prevalence for bar workers with the corresponding rates in the general population sub-sample (Table II). As cotinine-validated data were not available for the general population, we used the self reported smoking status for the bar workers which vary slightly from the partially cotinine-validated estimates. The overall prevalence of smoking in the general population sub-sample was $28.3 \%$ compared to $54.3 \%$ in bar workers. As the age and gender distributions differ, we compared gender- and age-specific rates. Higher prevalence rates in bar workers were observed for both genders and both occupational classes. Among bar workers, women (65\%) were more likely to be smokers than men (49\%) $(\mathrm{p}=0.07)$, whereas almost equal proportions of men and women $(29.1 \%$ vs $27.5 \%$ ) in the general population sub-sample were smokers. The gender difference was particularly striking in bar workers classified as managers: $37.5 \%$ of male managers smoked compared to $66.7 \%$ of female managers. This pattern in managers was not observed in the general population sub-sample. Bar workers also had substantially higher rates within the younger age groups, especially the 18 to 28 year olds. Comparison of the older age groups was limited due to the small numbers of bar workers. 


\section{Bar worker cigarette consumption in comparison with the general population sub-sample}

The mean number of cigarettes consumed (self reported) by bar workers was 16.7 ( $\mathrm{SD}=11.5)$ per day, similar to the 16.9 ( $\mathrm{SD}=9.8$ ) per day consumed by the general population sub sample (Table III). In the general population sub-sample, men consumed more cigarettes than women (19 versus 15 cigarettes per day, $\mathrm{p}=0.018)$; this gender difference was not observed in bar workers $(\mathrm{p}=0.8)$. Consumption varied by age among bar workers $(\mathrm{p}=0.099)$ with the highest consumption rates in the 29 to 48 year age category. Average consumption for 29 to 48 year old bar workers was much higher than in the corresponding age groups of the general population but the confidence intervals of the estimates in bar workers were very wide. Among bar workers, comparison of average consumption between male and female staff and managers was constrained by the small numbers within these subcategories.

\section{Adjusted smoking prevalence}

In order to control for the differences in age, gender and occupation distribution between the bar worker sample and the general population sub-sample, three logistic regression models were built, one model for bar workers, one for the general population sub-sample and a final model comparing bar workers with the general population sub-sample taking age, gender and occupational class into account (Table IV). Due to small numbers in the older age groups, the age categories ' $49-58$ yrs' and ' $59-78$ yrs' were combined.

Bar workers were more than twice as likely to be smokers as the general population sub-sample (adjusted $\mathrm{OR}=2.15,95 \%$ confidence limits 1.45 to $3.17, \mathrm{p}<0.01$ ). In all three models age was an independent predictor of smoking with generally decreasing prevalence by age. Neither gender nor occupational class were found to be independent predictors of smoking status in any of the models.

\section{Discussion}

\section{Main findings}

One of the study objectives was to establish a reliable estimate of smoking prevalence and consumption in bar workers. Due to the random sampling methods employed, the high response rate and the use of validated smoking status, this study provides to our knowledge the best estimate available of smoking prevalence in this occupational group. At $58 \%$, the smoking prevalence among Cork bar workers is extremely high, higher than in other similar studies. ${ }^{56}$ A higher prevalence rate 
(83.3\%) was found in male Asian American restaurant workers in Boston. ${ }^{14}$ However Averbach's estimates were based on a convenience sample and are not generalisable to a larger population.

The social and cultural environment in Ireland may influence bar workers' smoking behaviour. A strong tradition of alcohol consumption and its association with smoking within the pub culture in Ireland meant that bar workers were continuously surrounded by smoke and alcohol with possible 'normalisation' of smoking. This may partially explain the magnitude of this group's smoking prevalence. Another explanation may be that smokers, especially young smokers, are attracted to the pub trade. In our sample, the mean age bar workers started smoking was 17.7 years of age with female bar workers starting at a slightly younger age (17.3 years) than males (18.0 years). Evidence on whether individuals were already smokers before they started working in the hospitality industry or whether they became smokers after they started working is best obtained by longitudinal studies.

Furthermore bar workers cannot be considered a homogeneous group. In our study they comprised bar owners, managers, and temporary and permanent staff with different socio-economic positions. As higher smoking rates are commonly observed within lower occupational and social classes in developed countries, we conducted class specific analyses. As expected, bar staff had a significantly higher prevalence of smoking than bar managers.

Another objective was to estimate the adjusted odds of being a smoker for Cork bar workers relative to the general population (sub-sample) adjusted for age, gender and occupational class. Bar workers had more than double the odds of being a smoker than individuals in the general population subsample. This result highlights the magnitude of smoking as an issue in this unique population. Interestingly, age remained an independent significant predictor of smoking in both samples.

The present study has established a baseline prevalence among bar workers which can be contrasted with post-ban prevalence thereby clarifying the differential effects of workplace health protection measures on smoking behaviour.

\section{Limitations of this study}

Because of the random sampling strategy and the low refusal rate our results can be seen as representative of bar workers in a city area. Cork city is a small urban area comprising 123,000 citizens. It is possible that smoking behaviour among bar workers is different in rural areas; however we are confident that our sample also included people from rural backgrounds [Private addresses were 
available for seventy five participants (58\%); sixty (80\%) identified that they were currently living in Cork city and fifteen (20\%) identified that they were currently living outside the city]. We have no reason to expect significant differences in smoking patterns for bar workers within the RoI generally.

With regard to the telephone survey assessment of population smoking rates, there is likely to be under-sampling of some population groups such as foreign workers and students, who are less likely to have land lines. Smoking rates in such groups may differ from the general population. Other ROI general population surveys such as SLÁN ${ }^{15}{ }^{16}$ do exist but were either unavailable for our analysis or may be seen as out of date; we therefore consider our dataset to be the best estimate of smoking available for the general population.

Differences in methodology between the general population and bar worker samples limited comparisons. Bar workers were interviewed in a face to face interview while the general population were interviewed over the telephone, this may have introduced a bias into the general population data as some evidence suggests that interviewee are more likely to give socially desirable answers during a telephone interview in comparison to a face-to-face interview ${ }^{17}$. This difference may have inflated the odds ratio comparing the prevalence of bar workers with the prevalence of the general population. Coupled with the likely under-sampling of foreign workers and students, as mentioned above, this general population sample may underestimate the true smoking prevalence in Ireland. Classification of occupational class may not be completely comparable between the two samples but this should not affect the overall findings. And finally, different questions were used to assess self reported smoking status. Among the general population sub-sample, this was determined by the question: 'Do you smoke more than 1 cigarette per week?' Bar workers were asked whether they were current, occasional, ex or never smokers, which may have led to underestimation of smoking in very light smokers in the bar worker sample. However the availability of cotinine concentrations for most of the bar workers allowed us to identify non-reporting smokers. The fact that only five individuals were so re-categorised showed that bar workers' self reporting was reasonably accurate.

As cotinine concentrations were not available for 28 individuals, we were not able to validate all self reports. We cannot fully exclude systematic bias, i.e. that particularly smokers refused to provide a saliva sample. However we feel confident that the missing values did not introduce a major bias as only $14(50 \%)$ of those without cotinine samples were due to refusal [5 of whom were self reported smokers], while the rest of missing cotinine samples was caused by insufficient or contaminated samples [10 of whom were self reported smokers]. In addition missing cotinine values were fairly 
evenly distributed among smokers and non-smokers: 15 reported being smokers, 5 reported being exsmokers and 7 reported being never smokers. Re-analysis including only those individuals who had cotinine data $(n=101)$ showed rates that were generally very similar to those reported in Table II: a smoking rate (cotinine-validated) of $59.4 \%$ and a very similar distribution of smokers between the genders (53\% in males, $73 \%$ in females) and both occupational classes (managers 48\%, staff 69\%), but a slightly higher rate in the youngest age group of the 18 to 28 year olds (77\%).

Establishing baseline prevalence among this vulnerable occupational group will facilitate post-ban examinations of the impact of the smoking ban, a legal measure that is currently considered in several countries. The effect of the Irish smoking ban on passive smoking are well documented such as the reduction in exposure to second-hand smoke in non-smoking bar workers ${ }^{3}$, exposure to particulate matter and benzene ${ }^{18}$ and subsequent improvements in respiratory symptoms and respiratory health ${ }^{3}$ 18. However as the health consequences of active smoking are more pronounced than those of passive smoking, the impact of the ban on active smoking behaviour in addition to existing evidence of positive effects on passive smoke levels may constitute important scientific evidence for future policy planning.

\section{Acknowledgements}

We thank Sangeetha N Kalimuthu and Meenakshi Uppel, for help with interviewing; Ann Kelly for help with data entry, Dr. Tony Fitzgerald for statistics advice. We especially thank the bar workers who participated in this study.

\section{Conflicts of interest}

SA is a member of the Board of the Irish Office of Tobacco Control (unpaid position).

IJP is the unpaid chair of the Irish Research Institute for a Tobacco Free Society.

\section{Key Points}

- Prevalence of smoking in Irish bar workers is twice that of a comparable sub-sample of the general population. 
- Bar workers are an occupational group with an extremely high smoking prevalence. Coupled with the exposure to high levels of secondhand smoke before the smokefree workplace legislation this "double exposure" makes them a high risk group for smoking-related illnesses.

\section{References}

1. Jarvis M, Foulds J, Feyerabend C. Exposure to passive smoking among bar staff. British Journal of Addiction 1992;87(1):111-3.

2. Bates M, Fawcett J, Dickson S, Berezowski R, Garrett N. Exposure of hospitality workers to environmental tobacco smoke. Tobacco Control 2002;11(2):125-129.

3. Allwright S, Paul G, Greiner B, Mullally BJ, Pursell L, Kelly A, et al. Legislation for smoke-free workplaces and health of bar workers in Ireland: before and after study10.1136/bmj.38636.499225.55. British Medical Journal 2005;331(7525):1117-.

4. Mulcahy M, Evans DS, Hammond SK, Repace JL, Byrne M. Secondhand smoke exposure and risk following the Irish smoking ban: an assessment of salivary cotinine concentrations in hotel workers and air nicotine levels in bars 10.1136/tc.2005.011635. Tobacco Control 2005;14(6):384-388.

5. Jones S, Love C, Thomson G, Green R, Howden-Chapman P. Second-hand smoke at work: the exposure, perceptions and attitudes of bar and restaurant workers to environmental tobacco smoke. Australian and New Zealand Journal of Public Health 2001;25(1):90-3.

6. Bang K, Kim J. Prevalence of cigarette smoking by occupation and industry in the United States. American Journal of Industrial Medicine 2001;40(3):233-239.

7. Chapman S, Borland R, Scollo M, Brownson R, Dominello A, Woodward S. The impact of smokefree workplaces on declining cigarette consumption in Australia and the United States. American Journal of Public Health 1999;89(7):1018-1023.

8. Woodruff TJ, Rosbrook B, Pierce J, Glantz SA. Lower levels of cigarette consumption found in smoke-free workplaces in California 10.1001/archinte.153.12.1485. Archives of Internal Medicine 1993;153(12):1485-1493.

9. Brenner H FB. Smoking Regulations at the Workplace and Smoking Behavior: A Study from Southern Germany. Preventative Medicine 1994;23:230-234.

10. Longo DR, Johnson JC, Kruse RL, Brownson RC, Hewett JE. A prospective investigation of the impact of smoking bans on tobacco cessation and relapse 10.1136/tc.10.3.267. Tobacco Control 2001;10(3):267-272.

11. Fichtenberg C, Glantz S. Effect of smoke-free workplaces on smoking behaviour: systematic review. British Medical Journal 2002;325(7357):188.

12. Office CS. www.cso.ie.

13. Standard Occupational Classification. Second ed. London, 1995.

14. Averbach AR LD, Lam LJ, Sharfstein J, Cohen B, Koh H Smoking behaviours and attitudes among male restaurant workers in Boston's Chinatown: a pilot study. Tobacco Control 2002;11 34-37.

15. SLÁN. The National Health and Lifestyle Surveys Centre for Health Promotion Studies, Galway: National University of Ireland. Galway: Centre for Health Promotion Studies,National University of Ireland., 1999.

16. SLÁN. The National Health and Lifestyle Surveys Galway: Centre for Health Promotion Studies, National University of Ireland., 2003. 
17. Holbrook AL, Green MC, JA K. Telephone versus Face-to-Face Interviewing of National Probability Samples with Long Questionnaires: Comparisons of Respondent Satisficing and Social Desirability Response Bias. Public Opinion Quarterly 2003;67:79-125.

18. Goodman P, Agnew M, McCaffrey M, Paul G, L C. Effects of the Irish Smoking Ban on Respiratory Health of Bar Workers and Air Quality in Dublin Pubs. American Journal of Respiratory and Critical Care Medicine 2007;175:840-845. 